\title{
Dependence of lattice strain relaxation, absorbance, and sheet resistance on thickness in textured ZnO@B transparent conductive oxide for thin-film solar cell applications
}

\author{
Kuang-Yang Kou ${ }^{1}$, Yu-En Huang ${ }^{2}$, Chien-Hsun Chen ${ }^{3}$ and Shih-Wei Feng ${ }^{* 2}$
}

\author{
Full Research Paper

\section{Address:} \\ ${ }^{1}$ Department of Traffic Science, Central Police University, Taoyuan, \\ Taiwan, ${ }^{2}$ Department of Applied Physics, National University of \\ Kaohsiung, No.700 Kaohsiung University Road, Nan-Tzu Dist., 811. \\ Kaohsiung, Taiwan, and ${ }^{3}$ Green Energy and Environment Research \\ Labs, Industrial Technology Research Institute, Hsinchu, Taiwan \\ Email: \\ Shih-Wei Feng* - swfeng@nuk.edu.tw \\ ${ }^{*}$ Corresponding author \\ Keywords: \\ absorbance; low-pressure chemical vapor deposition; strain \\ relaxation; transparent conductive oxide; textured $\mathrm{ZnO}$
}

Beilstein J. Nanotechnol. 2016, 7, 75-80. doi:10.3762/bjnano.7.9

Received: 24 July 2015

Accepted: 08 January 2016

Published: 20 January 2016

Associate Editor: N. Motta

(c) 2016 Kou et al; licensee Beilstein-Institut. License and terms: see end of document.

\begin{abstract}
The interplay of surface texture, strain relaxation, absorbance, grain size, and sheet resistance in textured, boron-doped $\mathrm{ZnO}$ $(\mathrm{ZnO} @ \mathrm{~B})$, transparent conductive oxide (TCO) materials of different thicknesses used for thin film, solar cell applications is investigated. The residual strain induced by the lattice mismatch and the difference in the thermal expansion coefficient for thicker $\mathrm{ZnO} @ \mathrm{~B}$ is relaxed, leading to an increased surface texture, stronger absorbance, larger grain size, and lower sheet resistance. These experimental results reveal the optical and material characteristics of the TCO layer, which could be useful for enhancing the performance of solar cells through an optimized TCO layer.
\end{abstract}

\section{Introduction}

Thin-film solar cells require a transparent conductive oxide (TCO) to allow light to reach the absorber layers and create the electrical current. Due to its superior characteristics, including a wide band gap, high dielectric constant, high exciton binding energy (60 meV), high thermal stability, high transparency, and high conduction, wurtzite $\mathrm{ZnO}$ is a very promising TCO material used for the front contact, barrier layer, and intermediate reflector in solar cells [1-9]. Low-pressure chemical vapor deposition (LPCVD) can be implemented to deposit such a transparent, textured, and highly conductive TCO [9]. For thin- film solar cell applications, the LPCVD-grown $\mathrm{ZnO}$ can possess an as-grown textured structure to enhance light scattering and to increase the optical path through the solar cell without any post-treatment. Because the structural, optical, and electrical characteristics of LPCVD-grown $\mathrm{ZnO}$ are sensitive to the growth temperature, pressure, and flow rate, TCO can be tuned according to the application.

$\mathrm{ZnO}$ films grown on a sapphire substrate undergo residual strain induced by the lattice mismatch and the difference in thermal 
expansion coefficient [10]. Because strain can affect the electronic and optical properties of materials, the strain distribution in the films is an important subject to be investigated. The strain in $\mathrm{ZnO}$ films is accumulated during film growth and can be monitored by in situ optical reflectance measurement as a function of thickness, $t$ : compressive strain for $t<5.5 \mathrm{~nm}$, released compressive strain due to generation of misfit dislocations for $5.5 \mathrm{~nm}<t<200 \mathrm{~nm}$, tensile strain due to thermal stress for $200 \mathrm{~nm}<t<500 \mathrm{~nm}$, and residual tensile strain relaxed by microcrack formation for $t>500 \mathrm{~nm}$ [10].

The variation in the physical properties of nanostructures drastically influences the optoelectronic properties of $\mathrm{ZnO}$ [11-13]. $\mathrm{X}$-ray-excited optical luminescence of $\mathrm{ZnO}$ nanoneedles shows a sharp band gap emission and a broad red emission related to surface defects, while that of $\mathrm{ZnO}$ microcrystallites has a strong green emission due to defect states in the core [11]. A blueshifted absorption edge and photoluminescence caused by quantum confinement as well as a higher photovoltaic and sensor performance due to a larger surface area have been demonstrated in $\mathrm{ZnO}$ nanocrystals [14-16]. In addition, the microstructure, optical properties, and strain of thickness-dependent $\mathrm{ZnO}$ thin film grown by atomic layer deposition have been reported [17]. The thicker $\mathrm{ZnO}$ thin films show a larger crystalline grain, a smaller lattice strain, a higher $\mathrm{Zn} / \mathrm{O}$ ratio, and better crystal quality. Furthermore, doping impurities, such as B, Al, and Ga, can improve the electrical transport properties of $\mathrm{ZnO}$ [18]. There are two benefits to using a B-doped $\mathrm{ZnO}(\mathrm{ZnO} @ \mathrm{~B})$ film as the TCO layer. First, $\mathrm{B}$ has the smallest ionic radius among the three dopants $\left(\mathrm{B}^{3+}: 0.23 \AA, \mathrm{Al}^{3+}: 0.54 \AA, \mathrm{Ga}^{3+}: 0.62 \AA\right.$,), which results in better transparency. Second, a textured surface can be easily achieved for a $\mathrm{ZnO} @ \mathrm{~B}$ film grown by LPCVD, which can enhance light scattering and increase the optical path through the solar cell without any post-treatment. However, many important issues regarding optical and material characteristics in textured, $\mathrm{ZnO} @ \mathrm{~B}$ TCO grown by LPCVD for thin-film solar cell applications is yet to be explored.

This study reports the lattice strain relaxation, absorbance, and sheet resistance of textured $\mathrm{ZnO}$ TCO@B for solar cell applications. A thicker $\mathrm{ZnO} @ \mathrm{~B}$ film enhances the strain relaxation, resulting in an increased surface texture, stronger absorbance, larger grain size, and lower sheet resistance. The optimization of the TCO layer could be useful for enhancing the performance of solar cells.

\section{Results and Discussion \\ Structural characterization}

Four ZnO@B samples with 20-, 40-, 60-, and 70-minute growth times were prepared (here within named, $c-20, c-40, c-60$, and $c-70$, respectively). Figure 1 shows the atomic force microsco- py $(\mathrm{AFM})$ images $(5 \times 5 \mu \mathrm{m})$ of the four $\mathrm{ZnO} @ \mathrm{~B}$ samples. The surface roughness is $16.603,26.756,51.531$ and $56.233 \mathrm{~nm}$ for $c-20, c-40, c-60$, and $c-70$, respectively. Each sample is composed of small grains. The grain size of the triangular features is estimated to be $676,1520,2706$, and $4220 \mathrm{~nm}^{2}$ for $c-20$, $c-40, c-60$, and $c-70$, respectively. As the growth time (thickness) increases, the surface becomes more textured and the grain size larger. The film is composed of vertically stacked monocrystalline grains that appear as pyramids at the surface. The apparent texture structure in the sample $c-70$ can effectively scatter light to enhance the light coupling.

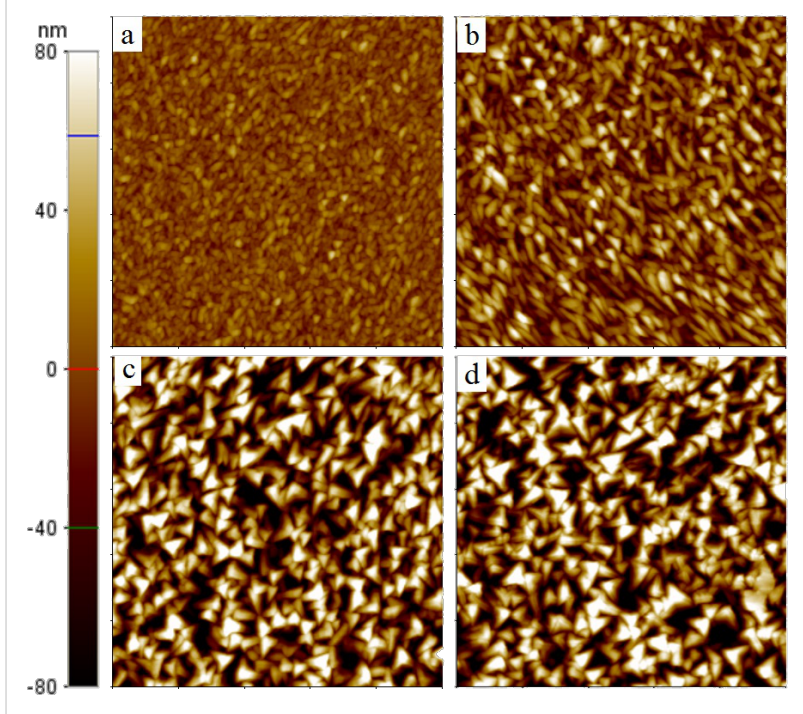

Figure 1: AFM images $(5 \times 5 \mu \mathrm{m})$ of (a) $c-20(16.603 \mathrm{~nm}),(\mathrm{b}) c-40$ (26.756 nm), (c) c-60 (51.531 nm), and (d) c-70 (56.233 nm) ZnO@B samples. The surface roughness of each sample is given in the parentheses.

Figure 2a-d shows scanning electron microscope (SEM) images of the $c-20, c-40, c-60$, and $c-70 \mathrm{ZnO} @ \mathrm{~B}$ samples, respectively. Figure 2e-h shows the panchromatic cathodoluminescence (CL) images of the corresponding SEM regions using an $11 \mathrm{kV}$ excitation electron voltage. In the SEM images, the $c-20$ sample is composed of small grains with no preferential orientation. Increasing thickness leads to an apparent textured structure and larger grain size. The CL image of the $c-70$ sample shows a high contrast and bright image, while that of the $c-20$ shows a low contrast and dark one. This shows that the apparent texture structure enhances light scattering.

Figure $3 \mathrm{a}-\mathrm{d}$ shows show the cross-sectional SEM images for the $c-20, c-40, c-60$, and $c-70 \mathrm{ZnO} @ \mathrm{~B}$ samples, respectively. From the cross-sectional SEM images of each sample, the thicknesses of the $c-20, c-40, c-60$, and $c-70$ samples are estimated to be $271.9,543.7,1,022$, and $1388 \mathrm{~nm}$, respectively. 


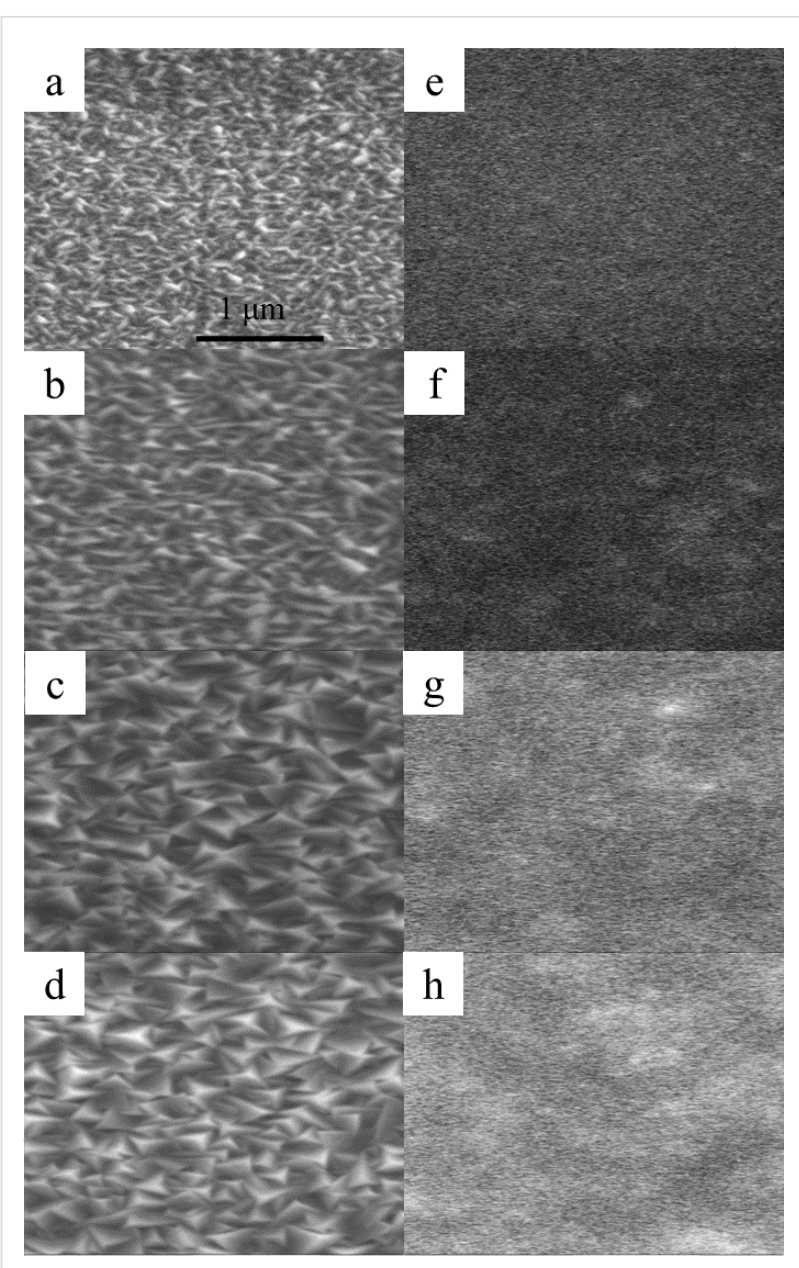

Figure 2: SEM images of the (a) $c-20$, (b) $c-40$, (c) $c-60$, and (d) $c-70$ $\mathrm{ZnO@B} \mathrm{samples} \mathrm{and} \mathrm{the} \mathrm{panchromatic} \mathrm{CL} \mathrm{images} \mathrm{(e),} \mathrm{(f),} \mathrm{(g),} \mathrm{and} \mathrm{(h),}$ respectively, taken over the same regions with $11 \mathrm{kV}$ excitation electron voltage at RT.

\section{Optical properties}

Figure 4 shows the CL spectra of the four samples at room temperature (RT). As the thickness increases, the CL emission peak is slightly red-shifted. An emission peak around $378 \mathrm{~nm}$ $(3.28 \mathrm{eV})$ is related to a band-to-band transition, while that in the $382-386 \mathrm{~nm}(3.21-3.24 \mathrm{eV})$ spectral range is due to transitions between band-tail states of $\mathrm{ZnO}$ [17]. Hence, as the thickness increases, the dominant red-shifted CL emission moves from the band-to-band transition to the transition between the band-tail states. Due to a larger grain size in the thicker $c-70$ sample, the red-shifted CL emission is consistent with the weaker quantum size effect.

Figure 5 shows the absorbance squared, $\alpha^{2}(E)$, of the four samples. Compared to the $c$-20 sample, the other three samples show enhanced absorbance in the $300-350 \mathrm{~nm}$ spectral range. As the thickness increases, the sharper, red-shifted absorption edge in the $360-380 \mathrm{~nm}$ spectral range is consistent with the

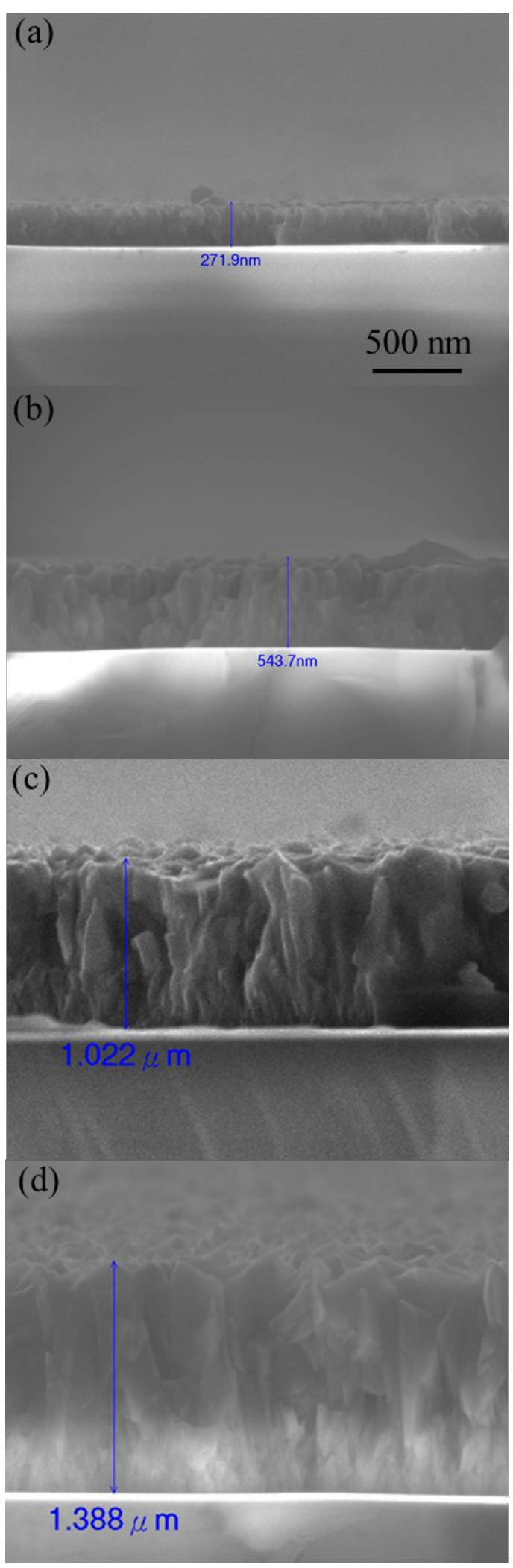

Figure 3: Cross-sectional SEM images of the (a) c-20, (b) c-40, (c) $c-60$, and (d) c-70 ZnO@B samples. The thickness of each sample is shown in the image. 


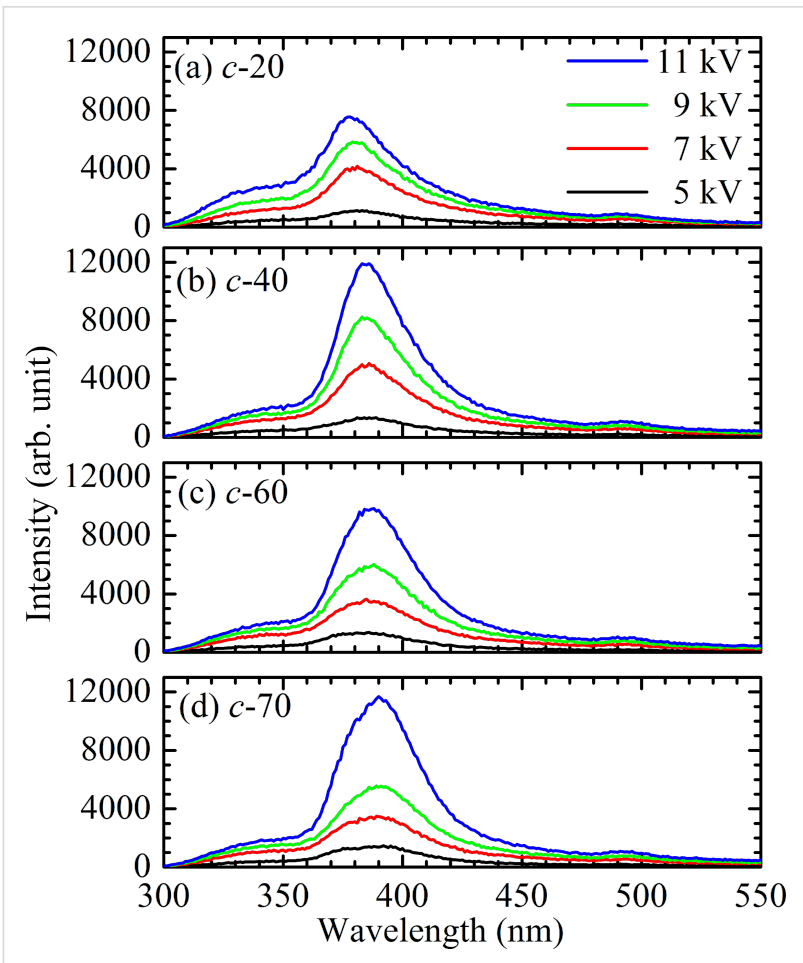

Figure 4: CL spectra of the (a) $c-20$, (b) $c-40$, (c) $c-60$, and (d) $c-70$ ZnO@B samples for excitations of $5,7,9$, and $11 \mathrm{kV}$ at RT.

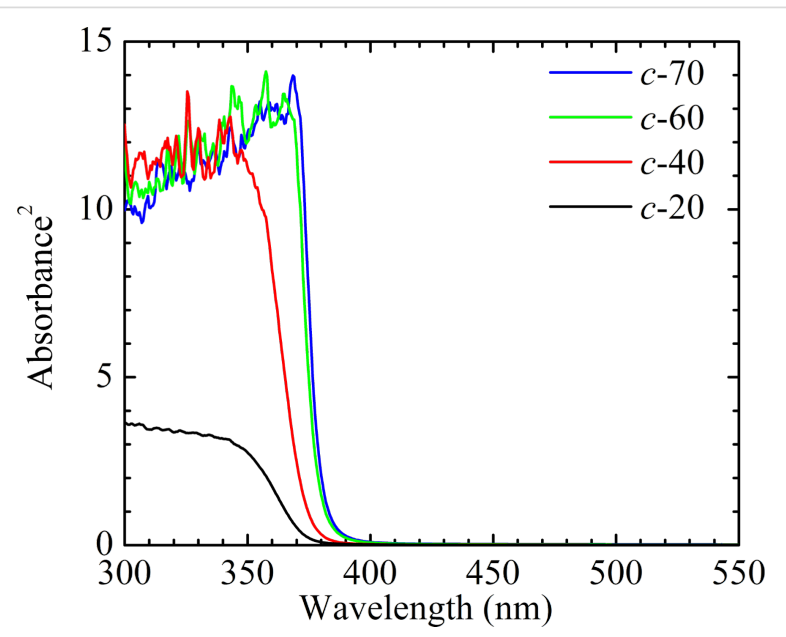

Figure 5: Absorbance (squared) of the four ZnO@B samples. more uniform distribution of grain size and weaker quantum size effect. The band gap energy, $E_{\mathrm{g}}$, of a semiconductor can be estimated by extrapolating the linear portion of the absorbance square to zero. As shown in Table 1, as the thickness increases, the red-shifted $E_{\mathrm{g}}$ is consistent with the weaker quantum size effect. The lower $E_{\mathrm{g}}$ of $\mathrm{ZnO} @ \mathrm{~B}$ samples compared to that of Al-doped $\mathrm{ZnO}$ (AZO or $\mathrm{ZnO@Al)} \mathrm{samples} \mathrm{is} \mathrm{beneficial} \mathrm{for}$ photon absorption and contributes to the quantum efficiency of solar cells [19].

\section{Strain relaxation}

To study the effect of thickness on strain relaxation, Raman measurements were taken to estimate the in-plane strain of the four samples. Figure 6 shows the Raman scattering spectra for the four samples. The spectra display $A_{1}(\mathrm{TO})$ and $A_{1}(\mathrm{LO})$ modes for $\mathrm{ZnO}$. The dotted lines at $379 \mathrm{~cm}^{-1}$ and $574 \mathrm{~cm}^{-1}$ show the strain-free $A_{1}(\mathrm{TO})$ and $A_{1}(\mathrm{LO})$ modes, respectively, for $\mathrm{ZnO}$ [20]. The in-plane strain in the $x$-direction, $\varepsilon_{x x}$, and in the $y$-direction, $\varepsilon_{y y}$, of $\mathrm{ZnO}$ films can be determined by the frequency shift, $\Delta \omega=\omega-\omega_{0}[21]$, as:

$$
\varepsilon_{x x}=\varepsilon_{y y}=-\frac{\Delta \omega\left(A_{1}(\mathrm{TO})\right)}{b-a\left(\frac{C_{33}}{C_{13}}\right)} \times \frac{C_{33}}{2 C_{13}}
$$

where $a=-774 \mathrm{~cm}^{-1}$ and $b=-375 \mathrm{~cm}^{-1}$ are the deformation potential constants of the $A_{1}$ (TO) mode [22]. The elastic stiffness constants, $C_{33}$ and $C_{13}$, are 216 and $104 \mathrm{GPa}$, respectively [1]. The six-fold symmetry of the hexagonal polar $c-\mathrm{ZnO}$ dictates an isotropic in-plane strain in the basal plane, i.e., $\varepsilon_{x x}=\varepsilon_{y y}=\varepsilon$. The frequency shift,s $\Delta \omega$, for the $A_{1}(\mathrm{TO})$ mode are shown in Table 1. The in-plane strain $\varepsilon$ can be deduced from Equation 1.

The in-plane tensile strain, $\varepsilon$, of the $c-20, c-40, c-60$, and $c-70$ samples is $0.0069,0.0682,0.1292$, and $0.0069 \%$, respectively. Figure 7 shows the evolution of in-plane strain for the four samples as a function of thickness. As the thickness increases, the in-plane tensile strain becomes larger and then relaxed. A similar trend, attributed to strain relaxation by microcrack forma-

Table 1: Thickness $(\mathrm{nm})$, grain size $\left(\mathrm{nm}^{2}\right)$, roughness $(\mathrm{nm}), E_{\mathrm{g}}(\mathrm{eV}), \Delta \omega\left(A_{1}(\mathrm{TO})\right)\left(\mathrm{cm}^{-1}\right), \varepsilon(\%)$, and sheet resistance $\left(R_{\text {sheet }}\right)($ ohm/ $\square)$ for the four ZnO@B samples.

\begin{tabular}{|c|c|c|c|c|c|c|c|}
\hline Sample & Thickness (nm) & Grain size $\left(\mathrm{nm}^{2}\right)$ & Roughness (nm) & $E_{g}(e V)$ & $\Delta \omega\left(A_{1}(\mathrm{TO})\right)\left(\mathrm{cm}^{-1}\right)$ & $\varepsilon(\%)$ & $R_{\text {sheet }}(\mathrm{ohm} / \square)$ \\
\hline$c-20$ & 272 & 696 & 16.603 & 3.32 & -0.082 & 0.0069 & 846 \\
\hline$c-40$ & 544 & 1,220 & 26.756 & 3.31 & -0.809 & 0.0682 & 191 \\
\hline$c-60$ & 1,022 & 2,706 & 51.531 & 3.28 & -1.534 & 0.1292 & 96 \\
\hline$c-70$ & 1,388 & 4,220 & 56.233 & 3.26 & -0.082 & 0.0069 & 76 \\
\hline
\end{tabular}




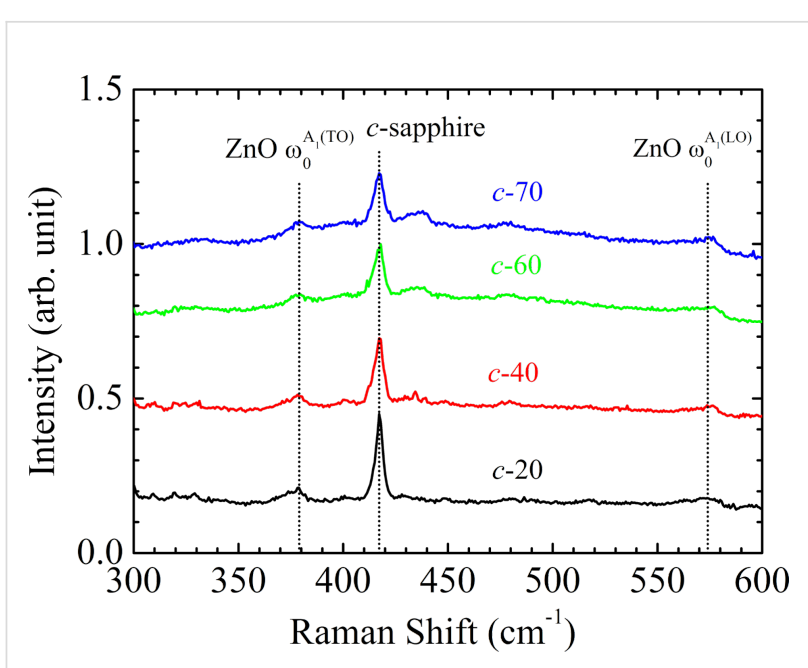

Figure 6: Raman scattering spectra of the four $\mathrm{ZnO@B} \mathrm{samples.} \mathrm{The}$ spectra display $A_{1}(\mathrm{TO})$ and $A_{1}(\mathrm{LO})$ modes for $\mathrm{ZnO}$. The dotted lines at $379 \mathrm{~cm}^{-1}$ and $574 \mathrm{~cm}^{-1}$ show the strain-free $A_{1}$ (TO) and $A_{1}$ (LO) modes, respectively, for $\mathrm{ZnO}$ [20].

tion, is also observed in the $\mathrm{ZnO}$ thin film grown by plasmaassisted molecular-beam epitaxy [10]. Therefore, for textured, $\mathrm{ZnO} @ \mathrm{~B} \mathrm{TCO}$, the residual strain induced by the lattice mismatch and the difference of thermal expansion coefficient is relaxed, leading to an apparent textured surface and larger grain size. The relaxed strain in the $c$ - 70 sample improves the sample quality, showing a lower sheet resistance. The lower sheet resistance and increased surface texture for the $c$-70 sample may represent the best TCO candidate. However, the stronger absorbance in the UV spectral range in the thicker TCO layer could decrease the quantum efficiency of the thin-film solar cell. To utilize the ZnO@B TCO on solar cells, the TCO layer must be grown on a solar cell and its optimal thickness thus could be chosen to match the overall material and structure of the cell.

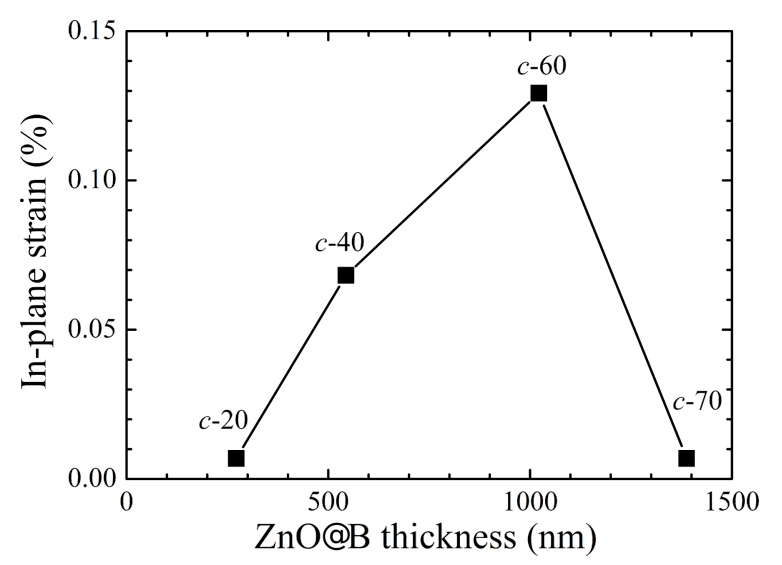

Figure 7: In-plane strain for the four $\mathrm{ZnO} @ \mathrm{~B}$ samples as a function of ZnO thickness.

\section{Conclusion}

In summary, a thicker, $\mathrm{ZnO} @ \mathrm{~B}$ TCO layer enhances the strain relaxation and hence shows an increased surface texture, stronger absorbance, less transparence, larger grain size, and lower sheet resistance. For solar cell applications, the TCO layer should be highly transparent and less resistive. Although the smaller sheet resistance and increased surface texture in thicker $\mathrm{ZnO} @ \mathrm{~B}$ samples are beneficial to device performance, photons in the UV spectral range are strongly absorbed in such a TCO layer and could limit the quantum efficiency of the thinfilm solar cell. For the application of $\mathrm{ZnO} @ \mathrm{~B}$ TCO in solar cells, the TCO layer must be grown on a solar cell and its optimal thickness therefore could be chosen to match the overall material and structure of the cell for enhancing the performance of solar cells. Nevertheless, this is an interesting and important subject which will be left for future investigation.

\section{Experimental}

\section{Synthesis of ZnO@B thin films by LPCVD}

The polar $c$-plane $\mathrm{ZnO}$ samples were grown on a sapphire substrate at $170{ }^{\circ} \mathrm{C}$ at a pressure of 0.6 Torr in a LPCVD reactor. DEZ and $\mathrm{H}_{2} \mathrm{O}$ were used as the precursors for $\mathrm{Zn}$ and $\mathrm{O}$, respectively. $\mathrm{ZnO}$ was doped with $\mathrm{B}$ to improve the electrical transport properties of $\mathrm{ZnO}$ thin films [9,18]. $\mathrm{B}_{2} \mathrm{H}_{6}$ was used as a doping gas. Four $\mathrm{ZnO} @ \mathrm{~B}$ samples with 20-, 40-, 60-, and 70-minute growth times, corresponding to $272,544,1022$, and $1388 \mathrm{~nm}$ in thickness, were prepared (samples $c-20, c-40, c-60$, and $c-70$, respectively). For the four samples, the $\mathrm{B}_{2} \mathrm{H}_{6}, \mathrm{DEZ}$, and $\mathrm{H}_{2} \mathrm{O}$ flow rates were 1,500 , and $550 \mathrm{sccm}$, respectively.

\section{Characterization}

The surface morphology was revealed by atomic force microscopy (Park Systems, XE-70) performed in noncontact mode using a silicon tip with a curvature of less than $10 \mathrm{~nm}$. The scanning electron microscope and cathodoluminescence results were acquired by the use of a Gatan monoCL3 spectrometer in a JEOL JSM 7000F SEM system. The absorption spectra were acquired with a U-3900 spectrophotometer (model 2J2-0015) at room temperature. The Raman spectra were recorded in the backscattering configuration using a Jobin Yvon-Horiba microRaman system (model T64000) with a $532 \mathrm{~nm}$ laser.

\section{Acknowledgements}

This research was supported by the Ministry of Science and Technology, Taiwan, R.O.C., under the grant MOST 103-2112M-390-002.

\section{References}

1. Morkoç, H.; Özgür, Ü. Zinc Oxide: Fundamentals, Materials and Device Technology; Wiley-VCH: Weinheim, Germany, 2007. doi:10.1002/9783527623945 
2. Özgür, Ü.; Alivov, Ya. I.; Liu, C.; Teke, A.; Reshchikov, M. A.; Doğan, S.; Avrutin, V.; Cho, S. J.; Morkoç, H. J. Appl. Phys. 2005, 98, 041301. doi:10.1063/1.1992666

3. Lai, C. M.; Huang, Y. E.; Kou, K. Y.; Chen, C. H.; Tu, L. W.; Feng, S. W. Appl. Phys. Lett. 2015, 107, 022110. doi:10.1063/1.4926978

4. Söderström, T.; Dominé, D.; Feltrin, A.; Despeisse, M.; Meillaud, F.; Bugnon, G.; Boccard, M.; Cuony, P.; Haug, F. J.; Faÿ, S.; Nicolay, S.; Ballif, C. Proc. SPIE 2010, 7603, 76030B. doi:10.1117/12.843511

5. Chen, X. L.; Liu, J. M.; Ni, J.; Zhao, Y.; Zhang, X. D. Appl. Surf. Sci. 2015, 328, 193-197. doi:10.1016/j.apsusc.2014.12.018

6. Shin, S. W.; Kim, I. Y.; Lee, G. H.; Agawane, G. L.; Mohokar, A. V.; Heo, G. S.; Kim, J. H.; Lee, J. Y. Cryst. Growth Des. 2011, 11, 4819-4824. doi:10.1021/cg2005387

7. Bikowski, A.; Ellmer, K. J. Mater. Res. 2012, 27, 2249-2256. doi:10.1557/jmr.2012.113

8. Slassi, A.; Ziat, Y.; Zarhri, Z.; Abdellaoui, M.; Fakhim Lamrani, A. Phys. Scr. 2015, 90, 085801. doi:10.1088/0031-8949/90/8/085801

9. Ellmer, K.; Klein, A.; Rech, B. Transparent Conductive Zinc Oxide Basics and Applications in Thin Film Solar Cells; Springer Series in Materials Science, Vol. 104; Springer: Berlin, Germany, 2008. doi:10.1007/978-3-540-73612-7

10. Park, S. H.; Hanada, T.; Oh, D. C.; Minegishi, T.; Goto, H.; Fujimoto, G.; Park, J. S.; Im, I. H.; Chang, J. H.; Cho, M. W.; Yao, T.; Inaba, K. Appl. Phys. Lett. 2007, 91, 231904. doi:10.1063/1.2813021

11. Armelao, L.; Heigl, F.; Brunet, S.; Sammynaiken, R.; Regier, T.; Blyth, R. I. R.; Zuin, L.; Sankari, R.; Vogt, J.; Sham, T. K. ChemPhysChem 2010, 11, 3625-3631. doi:10.1002/cphc.201000730

12. Dutta, S.; Chattopadhyay, S.; Sarkar, A.; Chakrabarti, M.; Sanyal, D.; Jana, D. Prog. Mater. Sci. 2009, 54, 89-136. doi:10.1016/j.pmatsci.2008.07.002

13. Li, D.; Leung, Y. H.; Djurišić, A. B.; Liu, Z. T.; Xie, M. H.; Shi, S. L.; Xu, S. J.; Chan, W. K. Appl. Phys. Lett. 2004, 85, 1601-1603. doi:10.1063/1.1786375

14. Vanheusden, K.; Seager, C. H.; Warren, W. L.; Tallant, D. R.; Voigt, J. A. Appl. Phys. Lett. 1996, 68, 403-405. doi:10.1063/1.116699

15. Sun, C. Q. Prog. Solid State Chem. 2007, 35, 1-159. doi:10.1016/j.progsolidstchem.2006.03.001

16. Prajapati, C. S.; Sahay, P. P. Sens. Actuators, B 2011, 160, 1043-1049. doi:10.1016/j.snb.2011.09.023

17. Chaaya, A. A.; Viter, R.; Bechelany, M.; Alute, Z.; Erts, D.; Zalesskaya, A.; Kovalevskis, K.; Rouessac, V.; Smyntyna, V.; Miele, P. Beilstein J. Nanotechnol. 2013, 4, 690. doi:10.3762/bjnano.4.78

18. Wang, G.; Li, Z.; Lv, S.; Li, M.; Shi, C.; Liao, J.; Chen, C. Ceram. Int. 2016, 42, 2813-2820. doi:10.1016/j.ceramint.2015.11.014

19. Xiao, S.; Zhou, J.; Huang, S.; Xiao, P.; Gu, X.; Yan, D.; Xu, S. J. Phys. D: Appl. Phys. 2015, 48, 305105. doi:10.1088/0022-3727/48/30/305105

20. Alim, K. A.; Fonoberov, V. A.; Shamsa, M.; Balandin, A. A. J. Appl. Phys. 2005, 97, 124313. doi:10.1063/1.1944222

21. Gruber, T.; Prinz, G. M.; Kirchner, C.; Kling, R.; Reuss, F.; Limmer, W.; Waag, A. J. Appl. Phys. 2004, 96, 289-293. doi:10.1063/1.1755433

22. Callsen, G.; Reparaz, J. S.; Wagner, M. R.; Kirste, R.; Nenstiel, C.; Hoffmann, A.; Phillips, M. R. Appl. Phys. Lett. 2011, 98, 061906. doi:10.1063/1.3554434

\section{License and Terms}

This is an Open Access article under the terms of the Creative Commons Attribution License

(http://creativecommons.org/licenses/by/2.0), which permits unrestricted use, distribution, and reproduction in any medium, provided the original work is properly cited.

The license is subject to the Beilstein Journal of Nanotechnology terms and conditions: (http://www.beilstein-journals.org/bjnano)

The definitive version of this article is the electronic one which can be found at: doi:10.3762/bjnano.7.9 